\title{
THE PHYSIOTHERAPIST'S RESPONSIBILITY
}

\author{
By W. WOODGATE, M.C.S.P. \\ HOSPITAL LIAISON OFFICER, WESTERN PROVINCE BRANCH.
}

T HE physiotherapist's responsibilities are ingrained from the commencement of his education. The word education is used rather than the word training because he does not only need practical training in specific skills. He is given the theory of his subjects to develop an understanding of his work, the crucial test of this understanding being his ability to advance it.

His profession is not learned in three months or even three years, but to master its activities requires a permanent study. It requires constant critical analysis and then modification by the results of this analysis. It is required to appreciate the things of intrinsic importance and then decide whether their attainment is a practical possibility. The surgeon or physician is concerned with getting the required physiotherapeutic result. The physiotherapist working under their guidance has the responsibility of deciding the best method of achieving this result.

\section{The Patient - Physiotherapist relationship}

Although emphasis has recently fallen on the need to treat patients as an entity and not a condition, physiotherapy is one of the medical services which has always done this, and is one of the last remaining services to do so. Once a patient feels he is being treated, or regarded, as a thing, a case, a condition, all hope of a professional relationship is lost and with it all hope of the co-operation necessary to achieve a perfect result.

As our field is primarily one of rehabilitation the fact that behind the case papers there is not an abstraction but a human being with his own characteristics, home, background work and family requires an acceptance of an individual and a personal sense of responsibility towards him. Therefore the physiotherapist must study the whole patient, must establish a personal contact, and may do more good by understanding personal difficulties, than by the operation of all his impedimenta.

When such personal relationships develop and the confidence thus established leads to improvement the physiotherapist is praised for exceptionally fine work. The reason lies beyond the manipulations of a technician but in a person exercising his initiative and respsnsibility.

\section{Selection of Patient and Treatment}

Owing to the understaffed and overcrowded hospital department an additional responsibility is thrown on the physiotherapist. He must not only select the treatment most suitable for the patient, which arises in many cases; but he must also select the patients most suitable to benefit from treatment. In selecting the treatment the temptation arises always to choose one treatment for the same diagnosis.

While the classroom sequence of Diagnosis, Signs, Symptoms, Aims of Treatment, Method of Treatment need not be followed lavishly for every patient, it would be unfortunate to progress from Diagnosis to method of treatment, without considering Aims of Treatment in the light of individual requirements.
The methods of treatment are wide including massage, movements, remedial exercises, and the many forms of electrotherapy, but the aims are of great importance. For example a typist with a wrist injury would be rehabilitated quicker, from a point of view of work if pronation was concentrated on, and not an equal time in pro- and supination. A violinist with stiffness of the joints of the left upper limb would not need a great range of elbow movement but would require wrist extension and supple fingers. Had the right upper limb been involved the elbow movements would assume more importance.

In selecting the patients most suitable to benefit from treatment the problem arises from the state of affairs where an average of thirty and on occasions as many as forty or fifty patients have to be treated in a space of time originally recommended for the treatment of twenty. In addition many non-professional demands are made on the physiotherapist's time, varying from as low as $10 \%$ to as high as $30 \%$. It is accepted that the quality of the physiotherapist's treatment shall be 'his best'. But what of the quantity. The amount of time given to a case may not only determine the rate of progress, but whether there will be any progress at all. On what grounds can this time be allocated. Equality of time cannot be considered as it is ridiculous to propose spending as much time on a Colles fracture as a spastic child.

\section{The Time Factor}

Two means of allocating time unequally can be discussed; the severity of the condition, and the usefulness of the patient to the community. The former receiving priority coincides with the traditional point of view, but are we justified in spending additional time on a patient whose value to the community in terms of productive work is very low or nil? If the latter receives maximum treatment to ensure an early and efficient return to production the traditional view must be flaunted. This moral issue continually arises in a busy department and may be one of the hospital workers heavier responsibilities.

\section{Technique of Treatment}

This moral responsibility adds to the physiotherapist's personal responsibility of using certain acquired skills to the limit of his ability and knowledge, in the service of another individual.

A further responsibility lies in the very real danger of injury. The unskilful application of ultra violet light, short wave diathermy, ionisation, and remedial exercises in recent fractures, antenatal and cardiac conditions, can result in serious injury to the patient.

\section{Conclusion.}

It must be realised then, that the physiotherapist's responsibilities are not light. When all these decisions have to be made by an individual without the chance of consulting a more senior member of staff, such as in the case of one working single handed then the responsibilities are even heavier. 